\title{
Uso do smartphone e de aplicativos como ferramentas educacionais no ensino de Arte
}

\author{
El uso del smartphone y las aplicaciones como herramientas educativas en \\ la enseñanza del arte
}

\section{Use of the smartphone and applications as educational tools in Art teaching}

\author{
Jéssica Mami Makino \\ jmakino@usp.br
}

\section{RESUMO}

Neste texto apresento experiências educacionais realizadas com estudantes de graduação em Pedagogia, na disciplina de Arte. Procuramos utilizar o smartphone e aplicativos como meios de potencializar as experiências de mediação entre estudantes e obra de arte, e como recursos para promover o registro e reflexão dessas vivências. Para tanto, utilizamos os aparelhos que já eram de propriedade dos estudantes e softwares já instalados nos aparelhos, prescindindo novos gastos. Esses recursos foram utilizados para consultar imagens, biografias, críticas, bem como para registrar e portar reproduções de obras de arte vistas em museus. Ao final das experiências os estudantes tomaram para si o papel de mediadores em Arte, promovendo a aproximação entre o espaço museológico e pessoas de seu meio (familiares e amigos).

Palavras chave: Ensino de Arte, Smartphone, Aplicativos, Mediação Digital

\section{RESUMEN}

En este texto presento las experiencias educativas llevadas a cabo con estudiantes de licenciatura en Pedagogía, en la disciplina de Arte. Tratamos de utilizar el teléfono inteligente y las aplicaciones como medio para mejorar las experiencias de mediación entre los estudiantes y la obra de arte, y como recursos para promover el registro y la reflexión de esas experiencias. Para ello, utilizamos los dispositivos que ya eran propiedad de los estudiantes y el software ya instalado en los dispositivos, sin nuevos gastos. Estos recursos se utilizaron para consultar imágenes, biografías, reseñas, así como para registrar y llevar reproducciones de obras de arte vistas en museos. Al final de los experimentos, los estudiantes tomaron por sí mismos el papel de mediadores en el Arte, promoviendo la aproximación entre el espacio del museo y las personas de su entorno (familia y amigos).

Palabras clave: Educación Artística, Teléfono Inteligente, Aplicaciones, Mediación Digital

\section{ABSTRACT}

In this text I present educational experiences carried out with undergraduate students in Pedagogy, in the discipline of Art. We seek to use the smartphone and applications as a means to enhance the experiences of mediation between students and work of art, and as resources to promote the registration and reflection of these experiences. To do so, we use the devices that were already owned by the students and software already installed in the devices, without new expenses. These resources were used to consult images, biographies, reviews, as well as to register and carry reproductions of works of art seen in museums. At the end of the experiments, the students took for themselves the role of mediators in Art, promoting the approximation between the museum space and people from their environment (family and friends).

Keywords: Art Education, Smartphone, Applications, Digital Mediation 


\section{Introdução}

Relato, neste trabalho, como utilizei ferramentas digitais para otimizar o ensino de Arte em cursos de formação de pedagogos (professores polivalentes, unidocentes ou generalistas, diferentes nomes dados à mesma profissão no Brasil). O curso de Pedagogia em que sou docente tem como objetivo formar professores que atuarão na Educação Infantil e nas séries iniciais do Ensino Fundamental (primeiro ao quinto ano), além de serem preparados para administrar uma unidade educacional. Nesse contexto, o graduando deve conhecer a linguagem das Artes Visuais e da Música tendo experimentado diferentes vivências de criação, entrado em contato com obras de arte em espaços expositivos, realizado exercícios de mediação e planejamentos de proposições artísticas. A partir dessas experiências e do estudo de referenciais teóricos, espera-se que o pedagogo defenda a importância do ensino de Arte na Educação e possa atuar em parceria com o professor especialista de Arte ou Música. Neste texto vou ater-me às experiências transcorridas na área de Artes Visuais.

As atividades que serão descritas tinham duas funções: promover a experiência estética a esses estudantes e oferecer-lhes repertório de proposições para que fossem realizadas com seus próprios estudantes no futuro.

Embora o título deste trabalho possa sugerir, não pretendo fazer um elogio à tecnologia e nem desmerecer o trabalho com a concretude da experiência tátil/olfativa/visual da investigação de materiais. Gostaria, porém, de mostrar o quanto as ferramentas digitais podem complementar essa experiência. Tampouco desejo elogiar o investimento em compra de equipamento caros (como tablets, e notebooks). Gostaria, mesmo, de relatar como utilizamos recursos tecnológicos que já faziam parte da vida dos graduandos em Pedagogia e que o quanto esses recursos otimizaram o trabalho de ampliação cultural e os exercícios de mediação da obra de arte.

Para isso, organizo o texto a partir do uso de três recursos que ou já estão disponíveis nos aparelhos celulares ou que podem ser facilmente instalados. O primeiro é o aplicativo de mensagens. O segundo é o aplicativo de captura e compartilhamento de imagem via câmeras frontal e traseira do smartphone e, por último, o drive virtual ou armazenamento em nuvem.

\section{Aplicativo de mensagens}

O software de trocas de mensagens é muito prático para contatos triviais entre os estudantes de uma disciplina e o docente. Mas tem o seu valor potencializado quando utilizado como centro rápido de trocas de conteúdos de aula.

Durante uma aula expositiva, era possível rapidamente adicionar links para filmes e documentários, sites de museus, recomendações de leituras e instantaneamente toda a turma tinha acesso a essas informações.
Um segundo uso era a distribuição de reproduções de obras de arte. Essas reproduções poderiam ser ampliadas, ter os detalhes verificadas no tempo do olhar de cada estudante. Esse tempo pôde ser estendido para além do horário de aula e foi nesse uso que as imagens compartilhadas no aplicativo de troca de mensagens foram utilizadas em sua potencialidade: os estudantes relataram suas experiências repetindo às suas famílias as perguntas mediadoras realizadas em sala de aula. E quando as perguntas previamente elaboradas foram insuficientes para aproximar espectador e imagem, acabaram por elaborar outras por si próprios.

Essa possibilidade de "portar" as imagens permitiu que os estudantes fossem mediadores entre conhecimentos em Arte que aprenderam na universidade e as pessoas que estão em seu meio de convívio, mas fora da instituição.

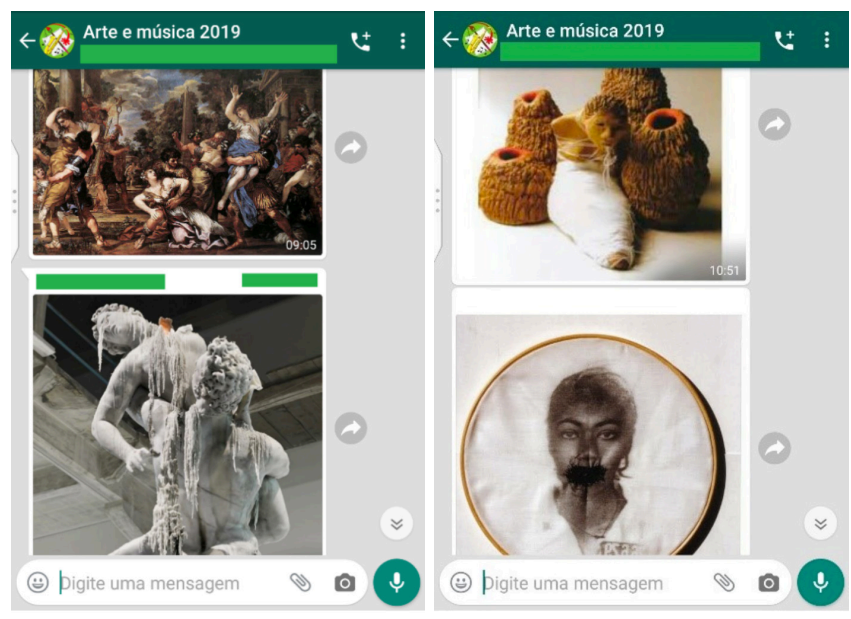

Figuras 1 e 2-Capturas de tela - aplicativo

Outra possibilidade de uso do aplicativo experimentada com os graduandos foi um exercício de elaboração de roteiro de apreciação de obras de arte. Obras de artistas como Rosana Paulino, Urs Fischer, Arissana Pataxó, Banksy, Heitor dos Prazeres, Mestre Didi, dentre outros foram disponibilizados para que os estudantes pudessem escolher uma para realizar proposições de mediação ao demais estudantes. Com o próprio celular pesquisavam a biografia dos artistas e notícias a respeito da obra de arte para poderem obter material para alimentar suas proposições, consultando verbetes em enciclopédias, galerias de arte, críticas e análises publicadas em revistas especializadas ou em seções de arte de jornais. As imagens foram compartilhadas no aplicativo, bem como as fontes de suas pesquisas. Ainda com os aparelhos em mãos, as imagens eram projetadas no quadro branco e as perguntas mediadoras provocavam os olhares dos estudantes que se alternavam entre projeção e tela do smartphone.

Outra fator positivo na manutenção dessas mensagens nos aplicativos foram seus usos extensivos aos amigos e familiares dos estudantes, mostrando que a portabilidade dessas informações permitiu a extensão dos saberes para além dos muros da universidade. 


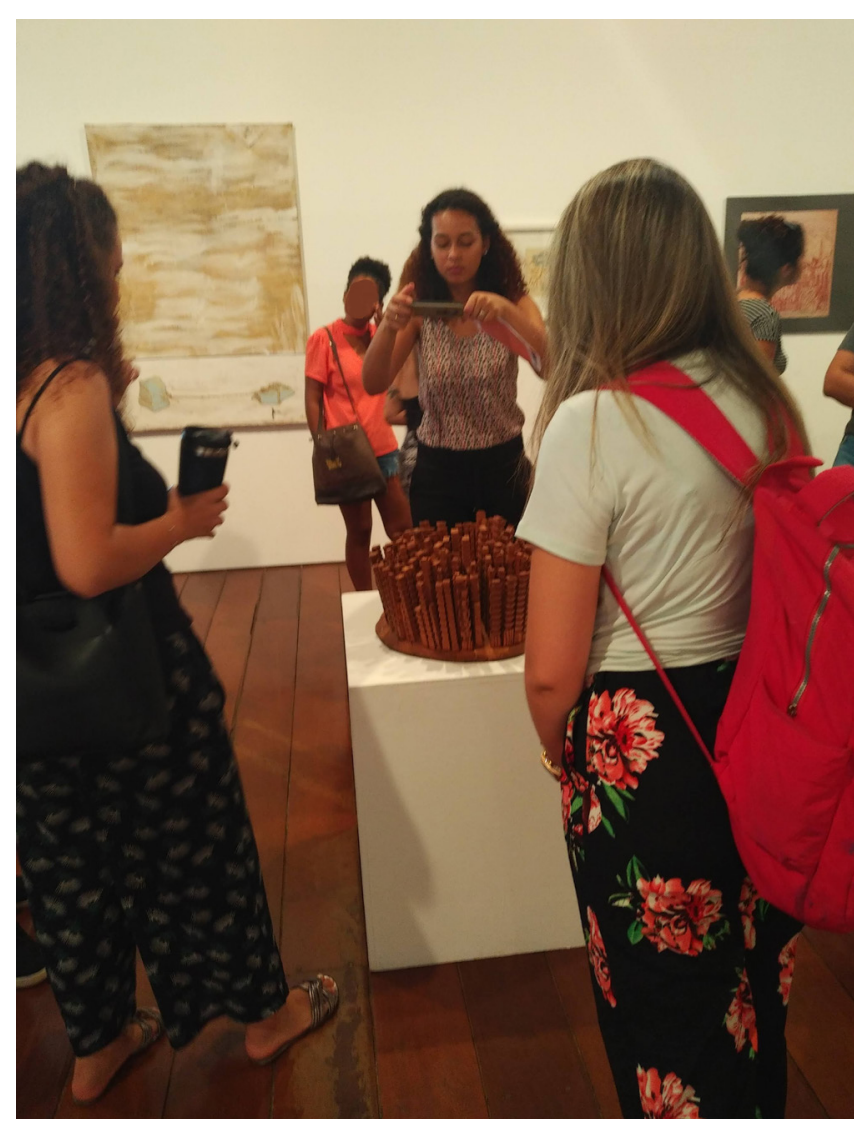

Figura 3 - Visita ao museu - arquivo pessoal

\section{Aplicativo de captura de imagem}

As idas a espaços museológicos foram experiências de muito aprendizado para os estudantes. Há muitos relatos de estudantes que nunca pensaram em entrar nos museus gratuitos da cidade. Às vezes, desconheciam a existência desses espaços mesmo tendo crescido na cidade ou região. As câmeras fotográficas presentes no aparelho celular registram essa descoberta, que foi tanto arquitetônica quanto artístico-cultural.

Além de se utilizar o próprio aparelho celular para fotografar as obras de arte em si, os estudantes foram orientados a observar as relações entre os trabalhos, como dialogavam entre si dentro da proposta desenhada pelo curador. Outra forma de registro muito comum entre os graduandos foi o uso da selfie em frente à obra de arte. Em alguns casos essas imagens foram compartilhadas em redes sociais (como Facebook e Instagram) divulgando o espaço e a exposição para pessoas que não tinham conhecimento de sua existência.

Uma imagem contendo pessoa, interior, mesa, sentado Descrição gerada automaticamenteNessa captura de imagem, o estudante

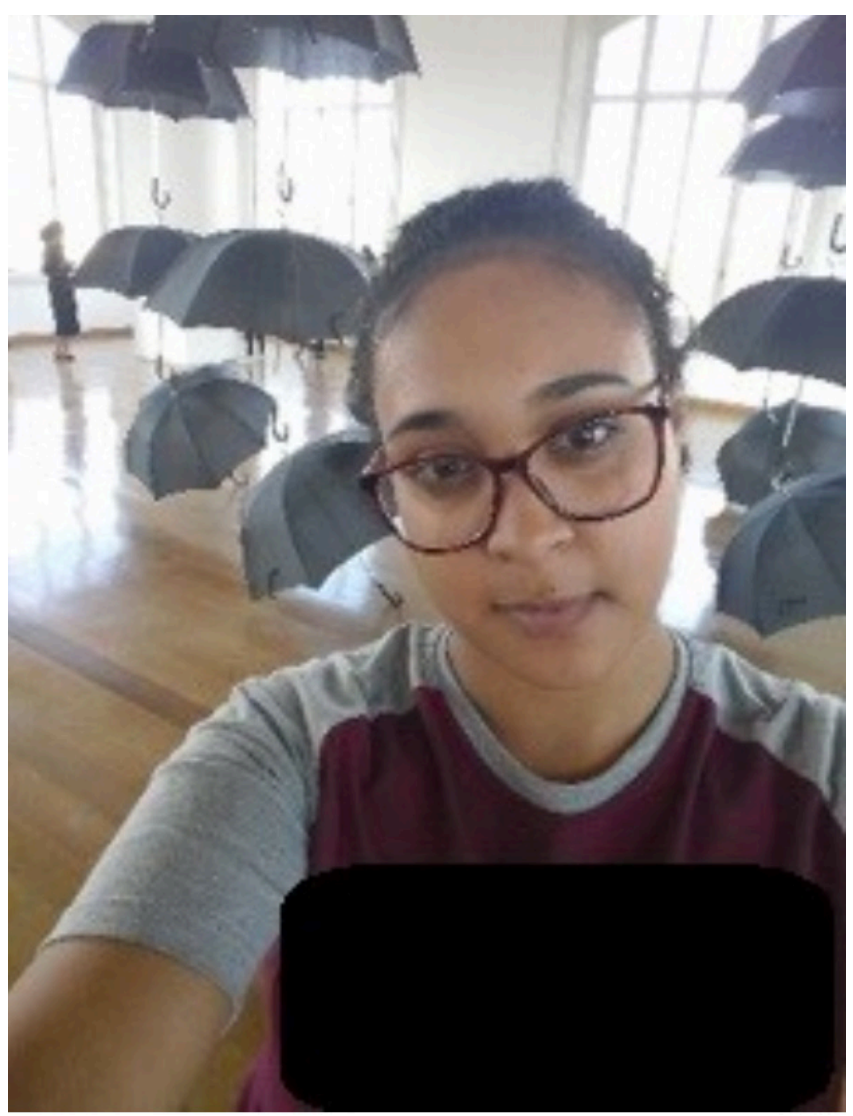

Figura 4 - Selfie de MS

transporta a obra de arte para públicos não especializados e promove deslocamentos e uso de espaços culturais que anteriormente lhes eram desconhecidos.

Se, por um lado, tirar uma selfie pode ser visto como uma ação narcisista dentro da pesquisa que Demarchi (2014, p. 60) realizou a partir de espectadores aleatórios em museus, por outro, na proposta educacional promovida no curso de Pedagogia, a selfie é uma forma de interagir e se misturar com a obra e o espaço. É um uma ação de aproximação e pertencimento.
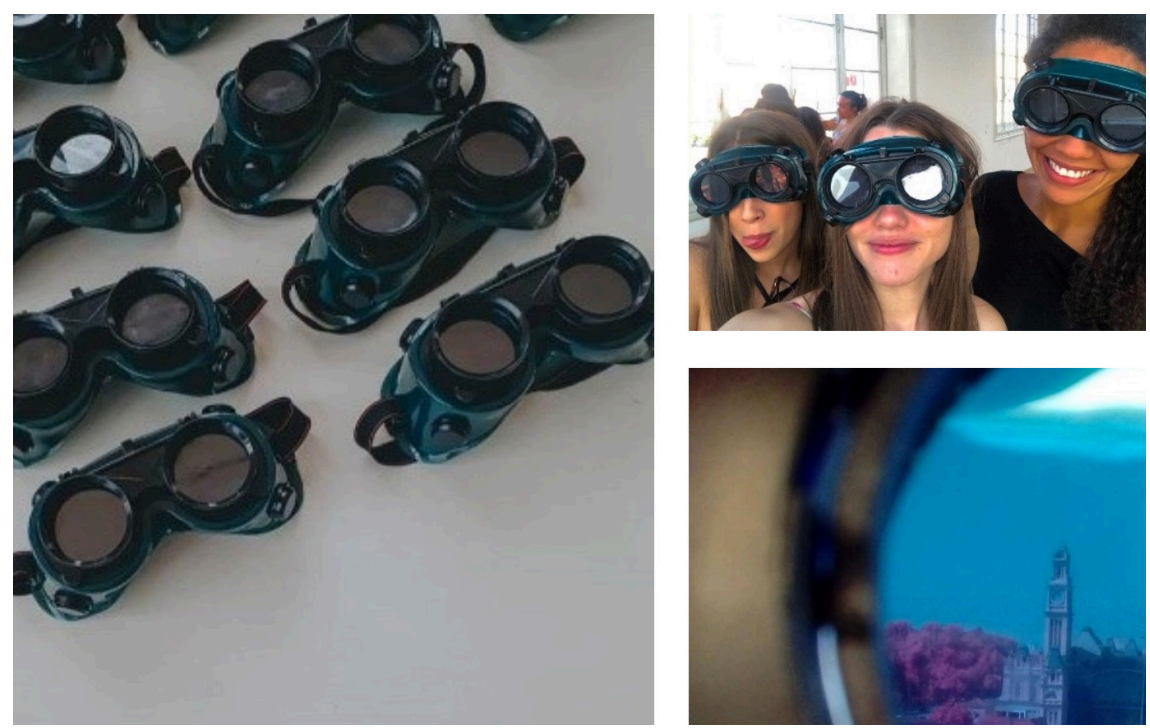

Figura 5 - Fotos de AM, AJ e SB 
Dentre as reflexões da pesquisa de Demarchi que mostram o uso das selfies como manifestação narcísica e consumista, há o sentido da posse da obra de arte e da afirmação do status social. Marcar-se em frente a uma obra mundialmente famosa, como La Gioconda de Leonardo Da Vinci é uma forma de mostrar aos amigos que se tem recursos para realizar uma viagem cara. No contexto da formação de pedagogos, também identifico esses dois sentimentos, o da posse e o da marca. Porém, no cenário educativo, a posse por meio da imagem e a afirmação de status por meio da presença no espaço expositivo são formas de colocar-se perante a sociedade como sujeitos que vencem as barreiras sociais, já que se trata de um curso composto de sujeitos oriundos de classes socioeconômicas pouco favorecidas.

Nesse caso, também, aponto a "portabilidade" da obra de arte como um ganho no processo educativo via mediação e afirmação. Isso se mostrou pelos relatos dos próprios estudantes que voltaram ao espaço museológico para levar a família, para que vissem pessoalmente o que tinham apreciado no pequeno monitor do smartphone.

\section{O uso do drive virtual}

Os relatos das visitas e os exercícios de mediação ficam salvos em pastas armazenadas em drives virtuais. Todos os estudantes têm acesso a essas pastas e podem conferir e comentar as imagens pesquisadas, os registros fotográficos e os relatos de experiência. Esse acesso é uma possibilidade de revisitar esses momentos e comentá-los, prolongando os debates acerca das leituras dos trabalhos, e, no caso dos relatos das visitas aos espaços museológicos, oferece a oportunidade de ler a forma como outros significaram a experiência. Finda a disciplina, todos os documentos são mantidos à disposição dos estudantes que podem utilizá-los posteriormente em seus próprios projetos.

\section{Considerações finais}

Em conferência de 2017, António Nóvoa reflete a respeito da revolução tecnológica que resulta na era digital que vivemos atualmente. Nessa reflexão diz que temos a chance de realizar o sonho da Escola Nova que era proporcionar autonomia investigativa aos estudantes. Nos tempos
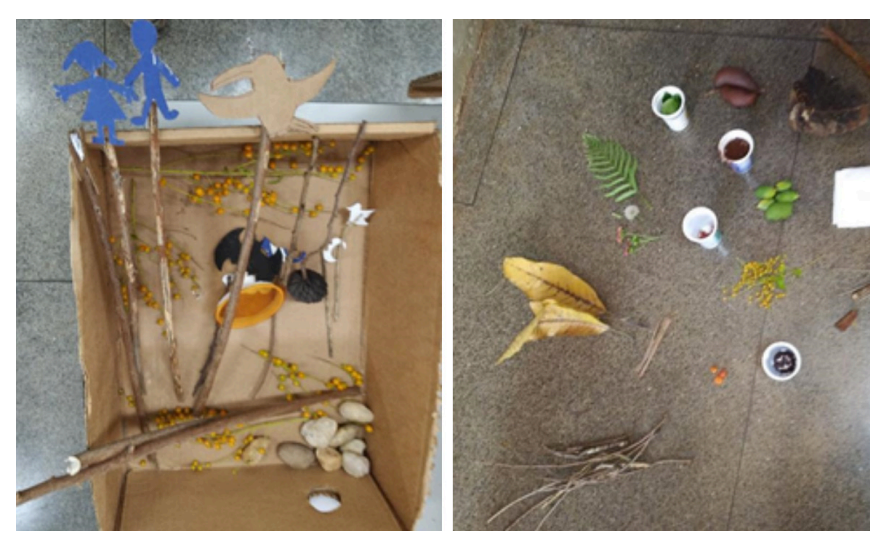

Figura 6 - Produções - arquivo pessoal atuais, essa possibilidade pode se tornar possível utilizando aparelhos como os smartphones, pequenos computadores com acesso a informações ilimitadas.

Leio a reflexão de Nóvoa nas experiências compartilhadas com os graduandos de Pedagogia. Vejo ainda mais, a possibilidade de formar em pouco tempo e com baixo custo multiplicadores, mediadores digitais das obras de arte que moram em museus. A possibilidade de "portar" as obras, bem como os comentários a respeito delas, sejam os tecidos por críticos de arte, sejam os realizados por amigos nas redes sociais, provocam movimentos, circulação, uma vez que faz do "portador" um mediador em potencial. Nas experiências aqui apresentadas, esses movimentos ocorreram tanto nos ambientes de comunicação virtual quanto nos ambientes reais, e, por vezes, transitando entre um ambiente e outro - como a selfie tirada no museu, vista na rede social e que provocou a vontade de outras pessoas irem conhecer os trabalhos de determinado artista.

Por essas razões, acredito na mediação digital e nos recursos do smartphone como potentes ferramentas auxiliares do ensino de Arte.

\section{Referências}

Demarchi, R. (2014). Ver aquele que vê: um olhar poético sobre os visitantes em museus e exposições de arte. Tese de Doutorados. São Paulo: Universidade Presbiteriana Mackenzie

Novoa, A. (2017). Firmar a posição como professor, afirmar a profissão docente. Cad. Pesqui., São Paulo , v. 47, n. 166, p. 1106-1133, dez. 2017. Disponível em:<http:// www.scielo.br/scielo.php?script=sci_arttext\&pid=S010015742017000401106\&lng=pt\&nrm=iso $>$. Acesso em: $31 / 01 / 2020$

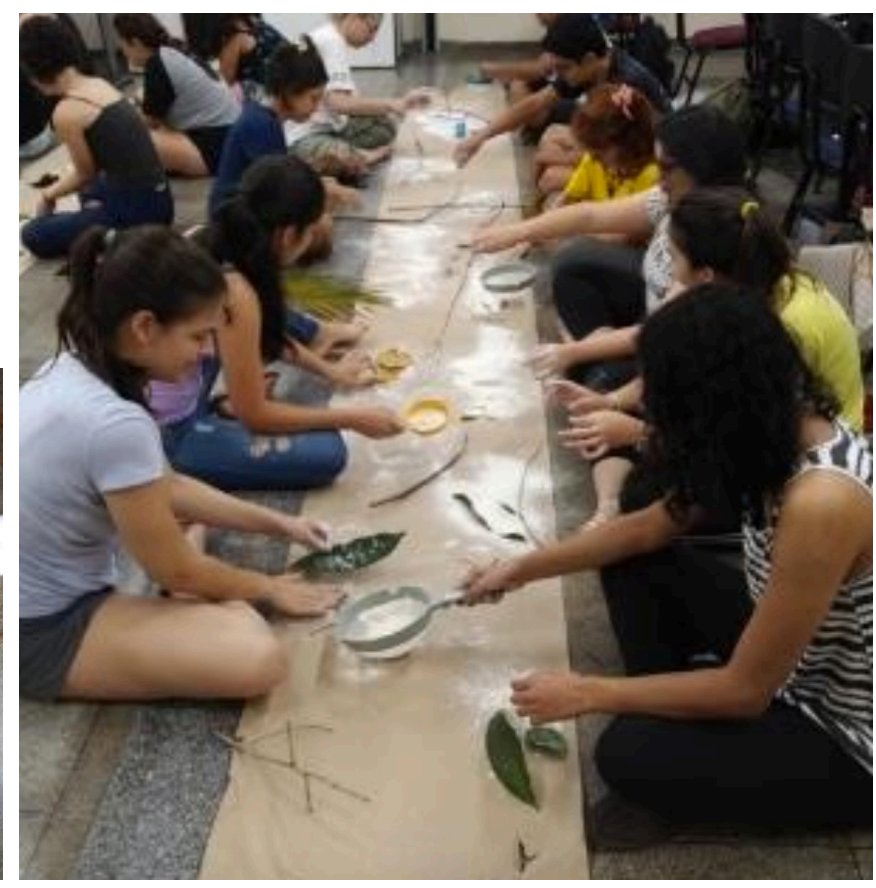

